Documento No. 6

\title{
ESTUDIOS DE MONEDA Y BANCA Y POLÍTICA MONETARIA SOBRE MÉXICO: SELECCIÓN BIBLIOGRÁFICA DE 1943 A 1978
}

Abril, 1979 
La primera parte de la presente bibliografía pretende ser una recopilación completa de los trabajos que, en materia de teoría y política monetaria, se han publicado sobre México desde 1965 hasta 1978.

La segunda parte, en cambio, consiste en una selección de estudios que aparecieron previamente en "Bibliografía Monetaria y Bancaria de México", Serie de Bibliografías Especiales No. 6, Banco de México, México 1965.

La Subdirección de Investigación Económica y Bancaria publica esta bibliografía para facilitar la labor de investigación de especialistas e interesados en la materia. La recopilación fue hecha por Fernando Salas.

$$
1965-1978
$$

Aspe, Pedro.

"Essays on the International Transmission Mechanism: The Mexican Case". Tesis Ph. D., MIT, 1978.

Bazdresch, Carlos

“La Política Monetaria Mexicana: Una Primera Aproximación” en Solís L. La Economía IV, México, D.F., Fondo de Cultura Económica, 1973.

Beltrán del Río, Abel

“A Macroeconometric Forecasting Model for Mexico: Specification and Simmulations". Unpublished Ph. D. Dissertation, University of Pennsylvania, 1973.

Beteta, Mario Ramón

“La Política Financiera en México, 1971-1976”, Documento Oficial, Comercio Exterior, p. 479, 1976.

Beteta, Mario Ramón

"La Política Bancaria de México”, Comercio Exterior, p. 341, 1974. 
Benet, Robert L.

The Financial Sector and Economic Development, The Mexican Case, Baltimore, The John Hopkins Press.

Bett, Virgil M.

“Central Banking in Mexico. Monetary Policies \& Financial Crises 1864-1940”. Michigan Business Studies, Vol. XIII, \# 1, Univ. of Michigan, Ann Arbor, 1957, pp. 123. Cita 58 de Boletín CEMLA.

Blejer, Mario I.

Dinero, Precios y Balanza de Pagos: La Experiencia de México, 1950-1973, CEMLA, 1976.

Blejer, Mario I.

“The Short Run Dynamic of Prices and the Balance of Payments", $\underline{\text { AER }}$, June, 1977.

Borja de Gala, Elisa.

"Nuevas Tasas de Encaje Legal”, en Comercio Exterior, p. 784, 1977.

Brothers, D. \& Solís L.

Mexican Financial Development, Austin, U. of Texas Press, 1965.

Bueno, Gerardo

"La Paridad del Poder Adquisitivo y las Elasticidades de Importación y Exportación en México". El Trimestre Económico, No. 162, 1974.

Buira Seira, Ariel

“Causas Principales y Efectos Internos de la Inflación”. Cincuenta Años de Banca Central, Fondo de Cultura Económica, 1976.

Carrillo Flores, Antonio.

"Acontecimientos Sobresalientes en la Gestación y Evolución del Banco de México", = Cincuenta Años de Banca Central, FCE, México, 1976. 
Cavazos Lerma, Manuel

"Cincuenta Años de Política Monetaria", Cincuenta Años de Banca Central, FEC, México, 1976.

Cavazos Lerma, Manuel

“La Opinión Pública y la Inflación en México”, IEPES, 1975.

CEMLA

Aspectos Financieros de las Economías Latinoamericanas, CEMLA, 1970. Ver nota Comercio Exterior, p. 160, 1970.

CEMLA

América Latina y Liquidez Internacional, CEMLA, 1970. Ver nota Comercio Exterior, p. $588,1970$.

CEMLA

Programación Financiera de Corto Plazo en Países Latinoamericanos, CEMLA, 1972. Ver nota en Comercio Exterior, 1972, p. 560.

CEMLA

$\underline{\text { Aspectos Financieros de las Economías Latinoamericanas, 1964. Ver nota en Comercio }}$ Exterior, 1965, p. 923.

Clavijo, Fernando

"Desarrollo y Prespectivas de la Economía Mexicana en el Corto Plazo. Un Modelo Econométrico Trimestral”. El Trimestre Económico, Vol. XLIII, No. 172, 1977.

Clavijo, F. Y Goméz O.

"El Desequilibrio y la Devaluación en la Economía Mexicana", El Trimestre Económico, 1976. 
Comercio Exterior.

"La Banca (Nacional) frente a las Prioridades del Financiamiento del Desarrollo", Comercio Exterior, p. 294, 1973.

Cervera Guzmán, Roberto.

"La Política Monetaria Mexicana en el Marco del Desarrollo Mexicano", Tesis, U.A. Puebla, 1972.

Córdova, Luis y Flores Caballero, Romeo.

“Protección y Libre Cambio: el Debate entre 1821 y 1826”, Comercio Exterior, 1971, p. 44.

Díaz de la Garza, G.

“Una Pequeña Duda de la Demanda de Dinero en el Caso de México y su Solución”, UANL, Tesis Licenciatura, Monterrey, 1973.

Diz, Adolfo, C.

Oferta Monetaria: un Modelo Simple Aplicable a América Latina, CEMLA, 1976.

Eckhaus, Richard A.

"The Structure and Performance of Mexican Banks and Financieras, 1940-1970", paper in the Workshop on Capital Market Development in Latin America, OAS, Bogotá, 1974.

Eckhaus, Richard A.

“Estructura del Sector de las Financieras en México 1940-1970”, Boletín CEMLA, Vol. XXI, Mayo, 1975, pp. 256-288.

Escobedo, Gilberto.

"Formulación de un Modelo para la Economía Mexicana", Boletín CEMLA, Vol. XXI, Febrero-Marzo 1975, pp. 58.70.

Escobedo, Gilberto.

"Los Indicadores de la Política Económica", s.e. hecho en FRB de Saint Louis, Oct. 1973. 
Escobedo, Gilberto.

"Los Indicadores para Medir el Resultado de la Política Monetaria en México", Comercio Exterior, Vol. XXIII, No. 10, 1973.

Espinosa de los Monteros, A.

“La Moneda en México", Revista de Economía \# 1, 1928.

Fernández Hurtado, Ernesto.

"Mayor Acento Expansionista de la Política Crediticia Mexicana”, Boletín CEMLA,p. 101, Marzo 1972.

Fernández Hurtado, Ernesto.

"Reflexiones sobre Aspectos Fundamentales de la Banca Central en México", Cincuenta Años de Banca Central, Fondo de Cultura Económica, México, 1976.

Fitzgerald, V.

"Patterns of Saving and Investment in México: 1939-1976" Working Papers Series No. 3, Cambridge: Center of Latin American Studies, 1977.

Fitzgerald, V.

Stabilization Policy in Mexico the Fiscal Deficit and Macroeconomic Equilibrium, 1960-1977. 1978 (a ser publicado en G.B.)

Genel, Julio A.

La Estrategia del Estado en el Desarrollo Financiero (México). CEMLA, México, 1977.

Genel, Julio A.

"The Problem of Naninflationary Financing: The Financieras Strategy", paper in Workshop on Capital Market development in Latin America, OAS, Bogotá. 
Gil Díaz, Francisco.

“Tres Temas Relevantes para una Política Monetaria y Fiscal”, en Cincuenta Años de Banca Central. Fondo de Cultura Económica, 1975.

Ghiggliazza, Sergio.

"Programación Financiera a Corto Plazo: la Reciente Experiencia de México". Ver ILPES, Pag. 4.

Gómez Oliver, Antonio.

“La Demanda de Dinero en México”, Cincuenta Años de Banca Central, FCE, 1975.

Gómez Oliver, Antonio.

“Causas de la Devaluación”, (mimeo), CEMLA, 1977.

Gómez Urrutia, Napoleón.

"Estructura Financiera, Rentabilidad y Crecimiento en México", Comercio Exterior, 1975, p. 643.

Griffiths, B.

Mexican Monetary Policy \& Economic Development, N.Y., Praeger Pub., 1972, Bibl. 155161.

Hernández Cata, Ernesto.

"Internacional Movements of Private Financial Capital. An Econometric Analysis of the Mexican Case". Tesis Doctoral, Yale University, 1976.

Himes, James R.

“La Formación de Capital en México”, El Trimestre Económico, p. 153, 1966.

ILPES.

Discusiones sobre Programación Monetaria y Financiera, Siglo XXI, México 1972, p. 399. Ver nota Comercio Exterior, p. 561, 1972. 
Ize, Alain.

"El Financiamiento del Gasto Público en una Economía en Crecimiento: El caso de México". Banco de México, Subdirección de Investigación Económica y Bancaria, Documento de Investigación No. 2, 1978.

Ize, Alain.

"Política Macroeconómica en el Corto Plazo: una Reseña", Banco de México, Subdirección de Investigación Económica y Bancaria, Documento de Investigación No. 5, 1979.

Jaastad, Larry.

Some Notes on the Recent Balance of Payments Experience in Latin America, (mimeo) University of Chicago, 1976.

Koehler, John E.

Information and Policymaking, Mexico, Ph. D., Yale University.

Koehler, John E.

Economic Policy Making with Limited Information: The Process of Macroeconomic Control in Mexico. The Rand Corporation, 1968.

Lagunilla Iñarrity, Alfredo.

“Aceleradores Monetarios en América Latina”, Comercio Exterior, 1967, p. 461.

Lagunilla Iñarritu, Alfredo.

“La Bolsa en el Mercado de Valores de México...” Comercio Exterior, 1977, p. 605.

Landerson, Mark L.

“¿Una Trampla de Liquidez de Divisas para México?”. El Trimestre Económico, México, Abril-Junio, 1977.

López Portillo, José.

“México: Política Financiera y Situación Económica”, p. 380, Comercio Exterior, 1975. 
Marcos, Jesús.

"The Portafolio Behavior of Private Financial Institutions in Mexico". Tesis Doctoral, Columbia University, 1974.

Márquez, Javier.

"La Inflación en México: Causas, Políticas y Perspectivas”, Boletín Mensual CEMLA, p. 399, Sept. 1973, Vol. XIX, No. 9.

Martínez Le Carenche, Roberto.

Curso de Teoría Monetaria y Crédito. Ver Comercio Exterior, p. 467, 1969, en Textos Universitarios, U.N.A.M.

Mercado Escobedo, Jaime.

Mercado de Capitales y Política Financiera de México, Tesis U.N.A.M., 1968. Ver nota en Comercio Exterior, 1968, p. 1113.

Montemayor, Aurelio H.

“La Demanda de Dinero: Un Estudio Econométrico para México”, Tesis U.N.L., 1968.

Montemayor, Rogelio.

"An Econometric Model of the Financial Sector of Mexico", Ph. D. Thesis, s.e., University of Pennsylvania.

Murra, R.

"La Demanda de Dinero en México". Documento de Trabajo, El Colegio de México, 1978.

Nasef, El Sayed, Mohammed

Monetary Policy in Developing Countries: The Mexican case: An Econometric Study. Rotterdam U. Press, 1972.

Orci Gándara, L.

"La Programación Financiera en la Política Monetaria", Cincuenta Años de Banca Central, FCE, 1976. 
Ortíz M., Guillermo.

Capital Accumulation and Economic Growth: A Financial Perspective on Mexico, Ph. D., Stanford U., 1977 (versión en español a publicarse por el CEMLA en 1979).

Ortiz, G. Y Solís, L.

"Estructura Financiera y Experiencia Cambiaria: México 1954-1977” en Banco de México, Subdirección de Investigación Económica y Bancaria, Documento de Investigación No. 1, 1978.

Oteyza, José Andrés.

“La Política Monetaria del Desarrollo: El Caso de México”, Tesis Licenciatura, U.N.A.M., 1966.

Petricioli Iturbide, Gustavo.

"Política e Instrumentos de Orientación Selectiva del Crédito", Cincuenta Años de Banca Central, FCE, México, 1976.

Petricioli, Gustavo

"La Experiencia de la Banca Central en el Estímulo de Actividades en Zonas Relativamente Subdesarrolladas”, Boletín CEMLA, Vol. XXI, Agosto 1975, p. 477.

Petricioli, Gustavo.

“La Experiencia Reciente de México en la Lucha contra la Inflación”, Boletín CEMLA, p. 270, 1976 (Mayo).

Ramírez, Roberto

“...La Politíca de Inversión de Reservas en América Latina” en Estabilidad Monetaria y Desarrollo Económico, Arte y Cultura, México, 1968. 
Reynolds, C.

"Why Mexico's Stabilizing Development was Actually Destabilizing", U.S. Congress Subcommittee on Inter-American Economic Relations on Recent Development in Mexico and _Their Implications for the U.S., 1972.

Rizzo, Sócrates.

"Un Análisis de las Causas de Crecimiento de la Oferta y De manda de Dinero en México, 1955-1970”, UANL, tesis, 1972.

Sánchez Aguilar, Edmundo.

México: Deuda Externa y Operación de la Banca Privada Americana. Ver nota Comercio Exterior, p. 965, 1974. 
Bibliografía Monetaria y Bancaria: México

$$
1943-1964
$$

“Actividad aseguradora y mercado de capitales". El Mercado de Valores (México) año XVII, no. 43, oct. 28,1957 , p. 513.

Aguilar, M. Alonso

"Panorama del mercado de capitales en México". Bancos (México) año IV, no. 4, abr. 1, 1954, p. 6.

Aguilera S., Evangelina.

"El Banco Central en la política de desarrollo". México, Universidad Nacional Autónoma, 1958, Tesis Lic.

Alcocer, Mariano.

"Las instituciones privadas de crédito en México, de 1921 a 1950 su desarrollo histórico". Carta Mensual (México) v. VI, nos. 64-65, ago./sep., 1951, p.115.

“Algunas consideraciones sobre el mercado de valores en México". Examen de la Situación Económica de México (México) años XXXIV, no. 390, may. 15, 1958, p. 4.

"Percu du systéme bancaire mexicain actuel". La Revue de la Banque (Bruselas) año XVIII, no. 1, 1954, p. 31.

Aranda Fernández, Hilda.

“Crédito al comercio pequeño”. México, Cía. Visant de México, S.A., 1964, 108 p.

Aranda, Silvino y otros

"Mercado mexicano de valores". Selección de Estudios Latinoamericanos. Colección SELA.Nos.2021. México, Publicaciones Especializadas y Editorial LOA, 1964, 2v.

\section{Batiza, Rodolfo}

“Las sociedades de inversión”. Revista Bancaria (México) v.IV., no. 1, ene./feb., 1956, p. 447. 
Beckhart, Benjamín Haggot

"Banking systems". New York, Columbia University Press, 1954, 934 p.

Bernal Molina, Julián

"El mercado de valores en México”. El Trimestre Económico (México) v. XIV, no. 2, jul./sep., 1947, p. 167.

Beteta, Mario Ramón

"El Banco Central como instrumento del desarrollo económico de México". Comercio Exterior (México) v.I, no. 1, jul./sep., 1964, p. 23.

El papel del Banco de México en el financiamiento de las exportaciones. Economía Política (México) v.I, no. 1, jul./sep., 1964, p.23.

"El sistema bancario mexicano y Banco Central". México, Centro de Estudios Monetarios Latinoamericanos, 1964. 39 p.

"Tres aspectos del desarrollo económico de México". México, Publicaciones Especializadas y Editorial LOA, 1963. 153p. (Selección de Estudios Latinoamericanos, No. 16, Colección SELA).

Bett, Virgil

"Central banking in Mexico, monetary policies and financial crisses 1864-1940). Ann Arbor, University of Michigan, 1957. 123 p.

Bouquet, León

"Le dollar et les problemes monetaires de l'Amérique Latine". Revue Economique (Paris) mar. 1954.

Bracho, José Fernando

"La banca de inversión; las sociedades financieras en México". México. Universidad Nacional Autónoma de México, 1946, 165 p. (Tesis). 
Brothers, Dwight S.

"El financiamiento de la formación de capital en México, 1950-1961". Comercio Exterior (México) t. XIII, no. 12, dic. 1963, p. 901.

Bueno y Urquidi, Arturo

"Relaciones entre el mercado de dinero y el de capitales". Revista Bancaria (México) v. VI, no. 5, sep./oct., 1958, p. 364.

Calderón, Antonio

"Resultados de la política monetaria”. Revista de Economía (México) v. XIX, no. 6, jun. 15, 1956, p. 168.

Camacho Morales, José

“Apuntes para la historia financiera de México, 1959-1963”. México, Ediciones Tlacopac, 1963. 2v.

Campos Andapia, Antonio

"Las sociedades financieras privadas en México". México, Centro de Estudios Monetarios Latinoamericanos, 1963, 237 p.

Campos Salas, Octaviano

"Las instituciones nacionales de crédito". (En: México, Cincuenta años de revolución, v. I: La Economía). México, Fondo de Cultura Económica, 1960, p. 415.

"La intervención del Banco de México, S.A. en el mercado de valores". Revista Bancaria (México) v. VI, no. 3, may./jun., 1958, p. 220.

El sistema monetario mexicano. México, Edit. Cultura, 1946. 30 p.

Castrejón Hernández, Vidal

“La institución del fideicomiso en México”. México, Gráficos Galeza, 1957, 104 p.

Cervantes, Manuel

“La moneda en México”. México, 1954, 99p. 
"El control selectivo del crédito en el desarrollo económico de México". El Mercado de Valores (México) año XVI, no. 48, no. 26, 1956, p. 565.

"El crédito bancario y la política crediticia en México". Jornadas Industriales (México) no. 44, nov./dic., 1955, p. 43.

Crespo Ramírez, Adolfo

"El crédito en México y su control a través de la Banca Central". México, Universidad Nacional Autónoma, 1951. Tesis Lic.

Cueto, Héctor Hugo del

"Cuando el peso valía más que el dólar". Ensayo histórico de las devaluaciones monetarias en México. México, Talls. de la Impresora Juan Pablos, 1959. 401 p.

“Depósito legal para financieras”. El Mercado de Valores (México) años XVIII, no. 4, ene. 27, 1958, p. 41.

\section{Días Garza, Alfonso}

"Efectos de la devaluación en la economía mexicana". Carta Mensual (México) nos. 46-47, feb./mar., 1950, p. 493.

Nuestro destino monetario. Revista Bancaria (México) no. 3, mar./abr., 1955, p. 112.

Dueñas, Heliodoro

“Los bancos y la revolución”. México, Ed. Cultura, 1945, 271 p.

Emery, Robert F.

"Mexican monetary policy since the 1954 devaluation". Inter-American Economic Affairs (Estados Unidos) v. XII, Spring 1959, no. 4, p. 72. 
Escandón, Eustaquio

"La banca mexicana". Conferencia pronunciada en las sesiones celebradas en el Town Hall de Nueva York. Revista Fiscal y Financiera (México) v. XV, no. 86, ago. 31, 1954, p. 37.

Farrugia Reed, Alfredo

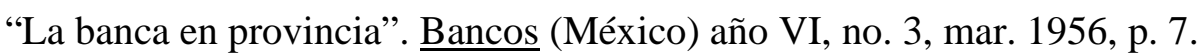

Fernández Hurtado, Ernesto y otros

Comentarios sobre "El peso mexicano, 1941-1949”, por Octavio G. De Bulhoes, Ernesto Fernández Hurtado, Juan F. Noyola Vázquez, Felipe Pazos y Rafael Urrutia. (En: Problemas Agrícolas e Industriales de México, v. V., no. 1.).

Fernández Hurtado, Ernesto y Eduardo Villaseñor

La expérience monétaire du Méxique; trad. Por L. De Azcárate. Paris, Presses Univeristaires de France, 1956.

Fernández Leal Avila, Roberto

"Los acontecimientos económicos de México y la política monetaria, 1929-1946”. México, s.e., 1963, 92 f. (mimeo).

Ferreiro, Elena

"Medidas de política monetaria y de créditos". Revista de Economía (México) v. XIX, no. 6, jun. 15, 1956, p. 162.

"Financiamiento industrial y banca privada". Examen de la Situación Económica de México (México) año XXXVIII, no. 439, jun. 15, 1962, p. 3.

"Fuentes de financiamiento". Examen de la Situación Económica de México (México) v. XL, no. 6, jun. 15, 1956, p. 147.

García Pacheco, Pedro

“Apectos históricos de la política monetaria2. Revista de Economía (México) v. IX, no. 6, ju. 15, 1956, p. 147. 
García Solórzano, Bulmaro

Problemas monetarios y del desarrollo económico de México. México, Avelar Hnos. Impresores, 1963, $344 \mathrm{p}$.

El redescuento como instrumento de control de crédito. México, Universidad Nacional Autónoma, 1950, Tesis.

Gaytán, Carlos

"The paper money of Mexico, 1822-1964", by Carlos Gaytán and Neil S. Utberg. Edigburg, Tex., 1963. $168 \mathrm{p}$.

Gazon Santafé, Antonio

XXVII Convención Bancaria, Apuntes marginales. Actividad Económica en Latinoamérica (México) año 1 , no. 10, may. $15,1961$.

Gómez, Rodrigo

La evolución de México y las bases fundamentales de la política monetaria. (Discurso pronunciado por Don Rodrigo Gómez, ante la XXX Convención Nacional Bancaria). El Mercado de Valores (México) año XXIV, no. 11, mar. 16, 1964, p. 137.

México y la libertad cambiaria. El Mercado de Valores (México) año XVI, no. 40, oct. 1, 1956, p. 474.

Gómez, Rodrigo

"Política anti-inflacionaria mexicana". Actividad Económica en Latinoamérica (México) año 5, no. 52, nov. 15,1964 , p. 5 .

González, Fernando A.

"Estructura del sistema bancario en México". Carta Mensual (México) v. V, nos. 46-47, feb./mar., 1950, p. 498.

Grove, David L.

"Política monetaria en países subdesarrollados". Centro de Estudios Monetarios Latinoamericanos. México, 1955, 112 p. 
Grove, David L.

"The potentialities of monetary policy in the economic development of Latin America. S.p.i. $22 \mathrm{f}$.

Gurza, Jaime

“Las funciones monetarias del Banco de México, S.A.”. México, s.e., 1941, 181 p.

Hornedo, Eduardo

"El Banco de México frente a la guerra”. El Economista Mexicano (México) t. VIII, no. 92, dic. 1942, p. 17.

Hunt, J. C.

"Latin American currency practices". The Banker (Londres) v. CVI no. 361, feb. 1956.

Influencia de la circulación monetaria en la producción de los bienes y servicios. Examen de la Situación Económica de México (México) año XXXIII, no. 377, abr, 15, 1957, p. 5.

Iturbide, Aníbal de

"La devaluación del peso mexicano y sus antecedentes". Revista de Economía (México) v. XI, no. 8, ago. 1948, p. 21.

Iturbide, Aníbal de

"La política de inversiones, la moneda y el crédito". $\underline{\text { Bancos }}$ (México) año VII, no. 7, jul. 1957, p. 8.

Joyce, Sherwood

Comparación entre la experiencia reciente en el uso de los cambios múltiples en América Latina y la obtenida en otros países que han empleado sistemas cambiarios similares. Doc. XV, no. 1957.

Keith Horsefield, J.

Inflation in Latin America. Staff Papers (Estados Unidos) v. I., no. 2, sep. 1950, p. 175.

Kock, M. H. De

Banca Central, apéndice sobre el Banco de México. México, Fondo de Cultura Económica, 1955. 
Kuri Breña, José

"Algunos problemas del sistema bancario mexicano". Revista Bancaria (México) v. V, no. 5, sep./oct., 1957, p. 430.

Lagunilla Iñarritu, Alfredo

"La tasa del dinero en México". El Trimestre Económico (México) v. VIII, no. 5, sep./oct., 1960, p. 386.

Latapí, Luis

“Desarrollo de la banca en México”. Revista Bancaria (México) v. VIII, no. 5, sep./oct., 1960, p. 386.

\section{Lobato López, Ernesto}

“El crédito en México, esbozo histórico hasta 1925”. México, Fondo de Cultura Económica, 1945, 318 p.

"La política monetaria mexicana”. Investigación Económica. (México) v. XVIII, no. 72, oct./dic., 1958, p. 557.

“La casa de moneda en México”. Bancos (México) no. 5, ago. 1951, p. 16.

López Rosado, Diego G.

Funciones y Desarrollo de la banca mexicana. Cursos de mejoramiento del personal. México, Banco de México, S.A., 1955. Ed. mimeográfica sin portada.

“La primera emisión de billetes en México”. Bancos (México) no. 4, jul. 1951, p. 12.

“La situación monetaria de México”. Investigación Económica (México) v. XIII, no. 4, 1953, p. 441.

McQueen, Charles A.

"Latin America postwar monetary standards". New York, The Monetary Standards Inquiry, 1943, 23 p.

Mainlan, John

"Peso stabilization”. Mexican-American Review (Estados Unidos) v. XII, no. 7, jul. 1949, p. 10. 
Manero, Antonio

"La revolución bancaria en México, 1865-1955; una contribución a la historia de las instituciones de crédito en México". México, Talleres Gráficos de la Nación, 1957, 354 p.

Manly, F.R.

"La banca regiomontana". Bancos (México) año VI, no. 1, ene. 1956, p. 7.

Márquez, Javier

"Controles selectivos del crédito de la banca privada". Boletín de Estudios Especiales (México) v. XIII, no. 146 , dic. 11,1958 , p. 33.

Márquez, Javier

Problemas de organización "banca central"; conferencias sustentadas por Javier Márquez, Ernesto Fernández Hurtado y Héctor Hernández. México, 1953, 11 f.

Martínez González, Jorge

"El tipo de cambio y la política económica; el caso de México”. México, Forma Print, 1963. 143 p.

Martínez Le Cllainche, Roberto

La politique monétaire et bancaire du Méxique. L'economie du Méxique d'aujourd'hui. Paris, Institut des Hautes Etudes de l'Amérique Latine, 1957. 220 p.

Martínez Ostos, Raúl

“Algunos aspectos de la política monetaria del Banco de México”. El Trimestre Económico (México) v. XI, no. 2, jul./sep., 1949, p. 209.

Maschke, Arturo

“Aprovechamiento de reservas monetarias de los países latinoamericanos". Panorama Económico (Chile) nov. 5, 1954.

\section{Mejía Ricart, Marcio}

“La asignación de inversiones y la inflación”. “Economía Política (México) v. I, no. 2, oct./dic., 1964, p. 35 . 
México, Comisión Nacional Bancaria

Legislación sobre el Banco de México. México, Depto. De Gráficas de la Sría. de Hacienda y Crédito Público, 1958. 436 p.

Monetary policy in Latin America. Monthly Review of Credit and Business Conditions (Estados Unidos) v. XXXVIII, no. 4, abr. 1956, p. 50.

Montes de Oca, Luis

“Cinco artículos sobre la devaluación monetaria”. México, s.e., 1954. 35 p.

Moore, O. Ernest

Evolución de las instituciones financieras en México. México, Centro de Estudios Monetarios Lationoamericanos, $1963.413 \mathrm{p}$.

Ortíz Mena, Raúl

Moneda y crédito. (En: México, cincuenta años de revolución, v. I: La Economía). México, Fondo de Cultura Económica, 1969, p. 387.

La moneda mexicana; análisis histórico de sus fluctuaciones; las depreciaciones y sus causas. México, s.e. 1942.151 p.

Pani, Alberto J.

Los orígenes de la política crediticia; con la réplica y las contrarréplicas suscitadas. México, Ed. Atlante, 1951, $205 \mathrm{p}$.

Pazos, Felipe

"Política monetaria y cambiaria latinoamericana". Comercio Exterior (México) t. VI, no. 10, oct. 1956, p. 481 .

\section{Pérez López, Enrique}

"El desarrollo económico y la estabilidad monetaria". El Trimestre Económico (México) v. XXV, no. 3, jul./sep., 1958, p. 378. 
Problemas monetarios de los países subdesarrollados. México, Banco Nacional de Comercio Exterior, S.A., 1959.12 p.

"Política crediticia”. Examen de la Situación Económica de México (México) no. 308, jul. 1951, p. 8; año XXX, no. 344, jul. 1954, p. 4.

"Política monetaria y crediticia durante 1956". Examen de la Situación Económica de México (México) año XXXII, no. 373, dic.15, 1956, p. 21.

“Política monetaria y crediticia durante 1957”. Examen de la Situación Económica de México (México) año XXXIII, dic. 15, 1958, p. 22.

“La reserva monetaria”. Panorama Económico (México) ene. 1956, p.1.

Ruiz Equihua, Arturo

El encaje legal; instrumento fundamental de la política monetaria mexicana contemporárnea. México, Ed. Cultura, T.G.S.A., 1963, 141 p.

Sánchez Cuén, Manuel

"El crédito a largo plazo en México, reseña histórica". El Banco Nacional Hipotecario Urbano y de Obras Públicas, S.A. 25 años de vida. México, Gráfica Panamericana, 1958. 301 p.

Siegel, Barry N.

Inflación y desarrollo; las experiencias de México. México, Centro de Estudios Monetarios Latinoamericanos, 1960, 199 p.

El sistema bancario mexicano, Actividad Económica en Latinoamérica (México) año 5,no. 53, dic. 15, 1964, p. 37.

Solís M., Leopoldo y Dwight S. Brothers

“El mercado de dinero y capitales en México". El Trimestre Económico (México) v. XXXI, no. 124, oct./dic., 1964, p. 578. 
Solís Ogarrio, Jorge

"El Fondo Monetario Internacional y los diversos grados de intensidad de la organización económica nacional”. Investigación Económica (México) v. IX, 1950, p. 403.

Szekely, Luis M.

Sobre la aplicación de modelos cuantitativos de decisiones para una política financiera a plazo corto y medio en México. México, Imprenta de "Pavia", 1963, 119 p.

Torres Gaitán, Ricardo

Política monetaria mexicana. “Caso México”. México, Lib. Ariel, 1944, 289 p.

Triffin, Robert

"Monetary development in Latin America"; reprinted from Federal Reserve Bulletin for June 1945. Washington, Board of Governors of the Federal Reserve System, 1945, 13 p.

Ugarte, Salvador

“Mexico’s Central Bank”. Mexican-American Review (México) v. XVIII, no. 1, ene. 1950, p. 16.

Urquidí, Víctor L.

“Tres lustros de experiencia monetaria en México: algunas enseñanzas". Memoria del Segundo Congreso Mexicano de Ciencias Sociales, v. II. México, 1946.

"Velocidad de circulación del dinero". Examen de la Situación Económica de México (México), año XXXIX, no. 447, feb. 1963 , p. 9. 